\title{
V. I. Kalmanovskii, Metodologiya dlya Khimikov: Uchebnoe Posobie (Metrology for Chemists: A Students' Textbook), Nizhni Novgorod: Izd. Yu. A. Nikolaeva, 2007, 132 pp.
}

DOI: $10.1134 / \mathrm{S} 1061934809120156$

A mandatory quality of chemical analysis is achieved by increasing the sophistication of the methods of analysis; additionally, the importance of metrology lies in the competent estimation of this quality, i.e., the reliability of the results obtained. Metrology of chemical analysis is undoubtedly an important part of the general theory of analytical chemistry. In his book, V.I. Kalmanovskii considered the basic data of the metrology of chemical analytical measurements. These data can be useful for experts who are familiar with quantitative chemical analysis and work in this area. The basic problems of metrology are considered only to the extent necessary for understanding the problems under discussion.

The following problems are covered: general information about measurement; measured values and the structure of the measurement process; units of physical quantities and the systems of units; the necessary information from statistics; the quality of measurements; traceability and uncertainty; calibration; procedures of quantitative chemical analysis; pure substances, standard samples, and certified mixtures; metrological service of the measuring equipment; international definitions of the basic metrological terms.

The manual can be used as a textbook for students of older years and graduate students of chemical higher educational institutions. It was recommended by the methodological commission of the Department of Chemistry of the Lobachevskii State University in Nizhniy Novgorod as a textbook for university students specialized in chemistry and chemical technology of inorganic substances and materials. The seven bibliographic sources are given in two lists, i.e., literature and normative specifications and technical documentation.

Ya. I. Yashin 